\title{
SIMULATION AND DESIGN OF REAL POWER CONTROLLED IPFC SYSTEM USING PSPICE
}

\author{
Sankar. S. ${ }^{1}$, Ramareddy. S. ${ }^{2}$ \\ ${ }^{1}$ Research Scholar, Sathyabama University, Chennai \\ ${ }^{2}$ Jerusalem College of Engineering, Chennai \\ Email: ${ }^{1}$ shankar_submanian@yahoo.co.in ${ }^{2}$ srrvictry@yahoo.com
}

\begin{abstract}
This paper describes closed loop controlled inter Line Power flow controller used in power system. An Inter line power flow controller is VSC-based FACTS controller for series compensation with the unique capability of power management among multilines of a subs-station. The FACTS technology is essential to alleviate these difficulties by enabling utilities to get most service from their transmission facilities. FACTS controllers can control series impendence, shunt impedance, current, voltage and phase angle. Different FACTS controller's circuits are simulated using PSPICE software package.IPFC is used to improve the power flow and to provide a power balance of a transmission system. The circuit model of IPFC was developed and the same is used for simulation.
\end{abstract}

Key Words FACTS, SSSC, IPFC, TCR, PSPICE.

\section{INTRODUCTION}

As a result of Flexible AC transmission system, considerable effort has been spent in recent years on the development of power electronics based power flow controllers [1]. They employ self-commutated inverters as synchronous voltage sources. The power electronics based voltage sources can internally generate and absorb reactive power without the use of capacitors and reactors. They can facilitate both real and reactive power compensation and thereby can provide independent control for real and reactive power flow [2, 3].

The Interline Power Flow Controller (IPFC) scheme proposed provides, together with independent controllable reactive series compensation of each individual line, a capacity to directly transfer real power between the compensated lines. This capability makes it possible to equalize both real and reactive power flow between the lines; transfer power demand from overland to under loaded lines; compensate against resistive line voltage drops and the corresponding reactive power demand; increase the effectiveness of the overall compensating system for dynamic disturbances[4,5]. The IPFC can potentially provide and effective scheme for power transmission management at a multi-line substation.

In the literature [1] to [9], the simulation of closed loop system with phase angle difference is not presented. In the present work ,the circuit model for closed controlled IPFC is developed and the same is used for simulation.

\subsection{Interline Power Flow Controller}

The basic principles of the Interline Power Flow Controller (IPFC) employs a number of DC to AC inverters each providing series compensation for different line as showing in Fig.1.1. The series compensation is provided by Static Synchronous Series Compensators [6].

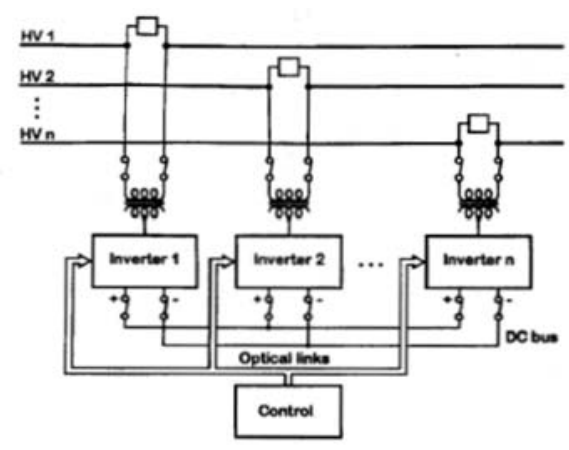

Fig.1. Block Diagram of an Inter line Power flow Controller

The Compensating inverters are linked together at the DC terminals. The compensators in addition to provide series reactive compensation can be controlled to supply real power exchange through the dc link from its own transmission line[7]. Thus surplus power available in underutilized lines is made available by other lines. This arrangement mandates the rigorous maintenance of the overall power balance at the 
common dc terminal by appropriate control action, using the general principle that the under loaded lines are to provide help, in the form of appropriate real power transfer, for the overloaded lines [8-10].

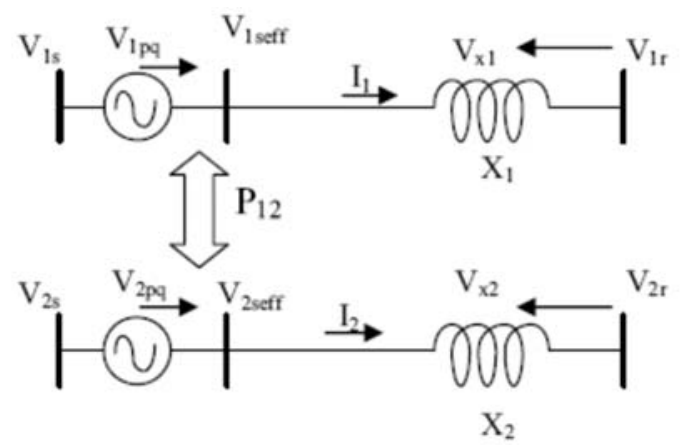

Fig. 2. Basic Interline Power flow controller

The elementary IPFC scheme consisting of two back-to back dc to ac inverters each compensating a transmission line by series voltage injection is shown in Fig. 2 Two synchronous voltage sources. with phasors $V_{1 p q}$ and $V_{2 p q}$ in series with transmission lines 1 and 2, represent the two back-to -back to dc to ac inverters. The common dc link is represented by a bi-direction link for real power exchange between the two voltage sources. Transmission Line 1, represented by reactance $X_{1}$, has sending ends bus with voltage phasor Vir. The sending end voltage phasor of line 2, represented by reactance $X_{2}$, is $V_{2 s}$ and the receiving end voltage phasor is $V_{2 R}$.

All sending end and receiving end voltages are constant with fixed amplitudes, $V_{1 s}=V_{1 R}=V_{2 s}=V_{2 r}=1 \mathrm{p} . u$, and with fixed angles resulting in transmission angles, $d_{1}=d_{2}$.

The line impedances and the rating of the two compensating voltage sources are identical, that his $V_{1 \text { pqmax }}=V_{2 \text { pqmax }}$ and $X_{1}=X_{2}=0.5$ p.u.

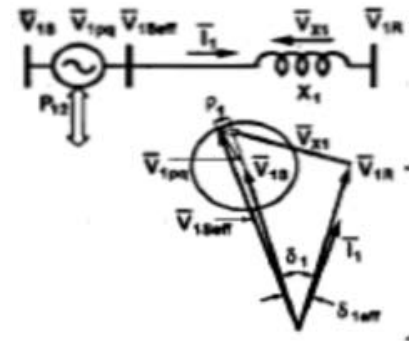

Fig. 3. For prime system and phasor diagram
Fig.3 is the phasor diagram defining to the relationship between $V_{1 s}, V_{x 1}$ and the inserted phasor voltage $V_{1 p q}$. The inserted voltage phasor $V_{1 p q}$ is added to the fixed end voltage phasor $V_{1 s}$ to produce the effective sending end voltage. The difference between $V_{1}$ self and $V_{1}$, gives the compensated voltage $V_{x 1}$, across, $X_{1}$. As $n$ is varied over its full 360 range, the end of phasor $V_{1 p q}$ moves along a circle with its centre at the end of $V_{1 s}$.'

The rotation of phasor $V_{1 p q}$ with angler1modulates both the magnitude and angle phasor $V_{x 1}$ and therefore both real power $\mathrm{P} 1 \mathrm{R}$ and reactive power Q1R vary with $\Pi$ in a sinusoidal manner as shown in Fig.4 The voltage source inventor $\left(V_{1 p q}\right)$ supplies or absorbs both real power (P1pq) and reactive power $(\mathrm{Q} 1 \mathrm{pQ})$, which are also a sinusoidal functions of angle $r$.
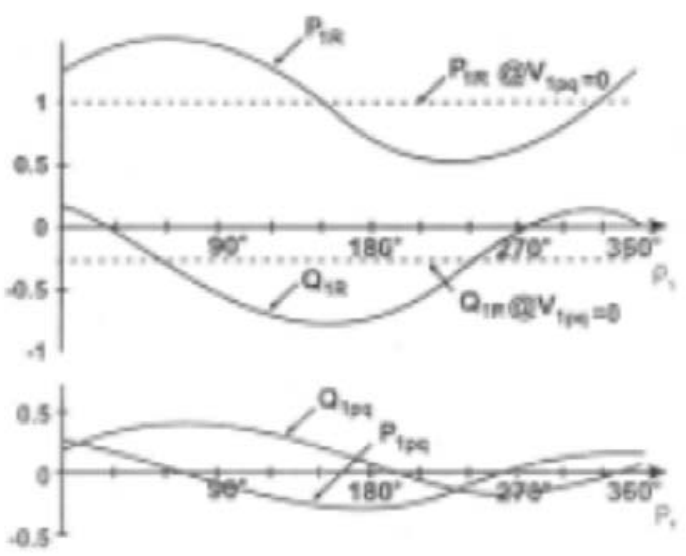

Fig. 4 Variation of the Real and Reactive Power with Respect to Phase Angle

II SIMULATION RESULTS

The circuit model of IPFC is shown in Fig 5a.In this model, the series transformers are represented as voltage depended voltage sources. The real power waveform without IPFC is shown in Fig. 5b.The real power wave form with IPFC is shown in Fig $5 \mathrm{c}$. From fig $5 c$, it can be seen that the real power is increased. 


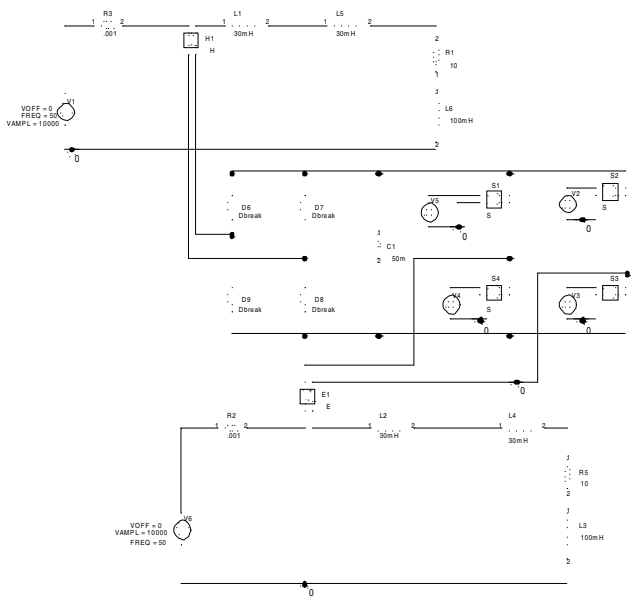

Fig 5a. Circuit model of IPFC with phase difference

The circuit model of IPFC with different values of voltages is shown in Fig .6a.Lines $1 \& 2$ operate at $11 \mathrm{kv}$ and $10 \mathrm{kv}$ respectively.

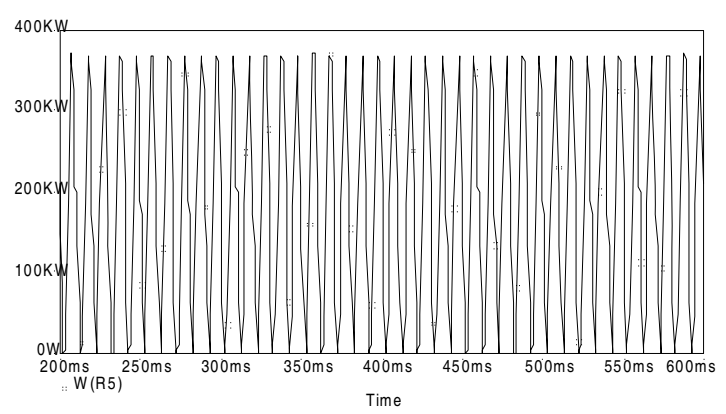

Fig. 5b. Real power without IPFC

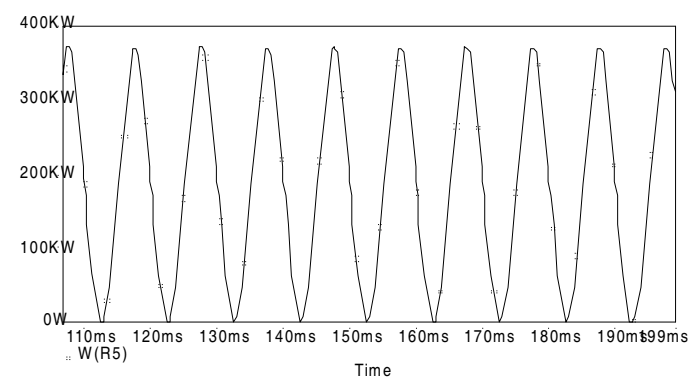

Fig. 5c. Real power with IPFC

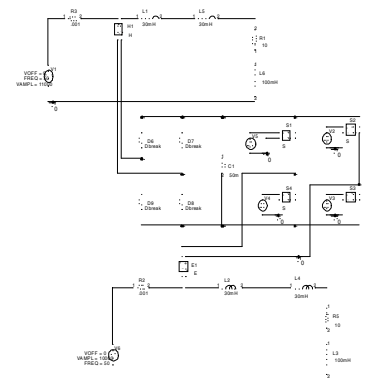

Fig. 6a. Circuit model of IPFC with different voltages.

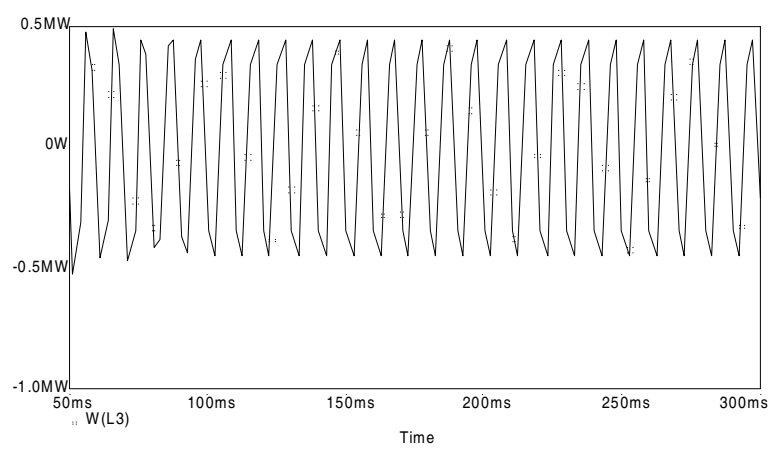

Fig. 6b.The Reactive power without IPFC

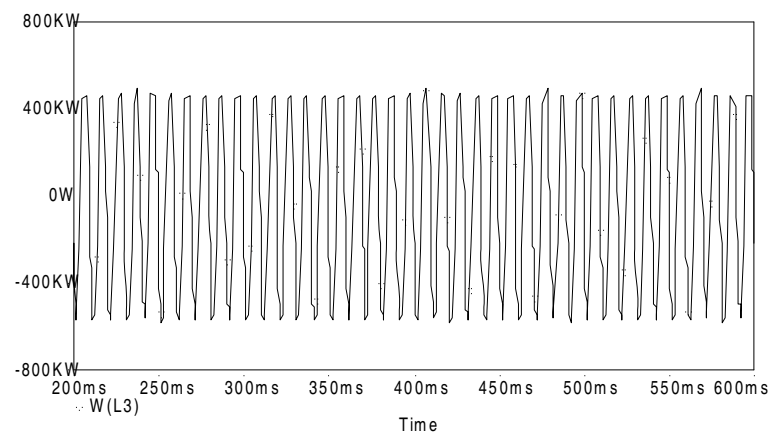

Fig. 6c.The Reactive power with IPFC

From Fig.6c, it can be observed that the Reactive power is increased.

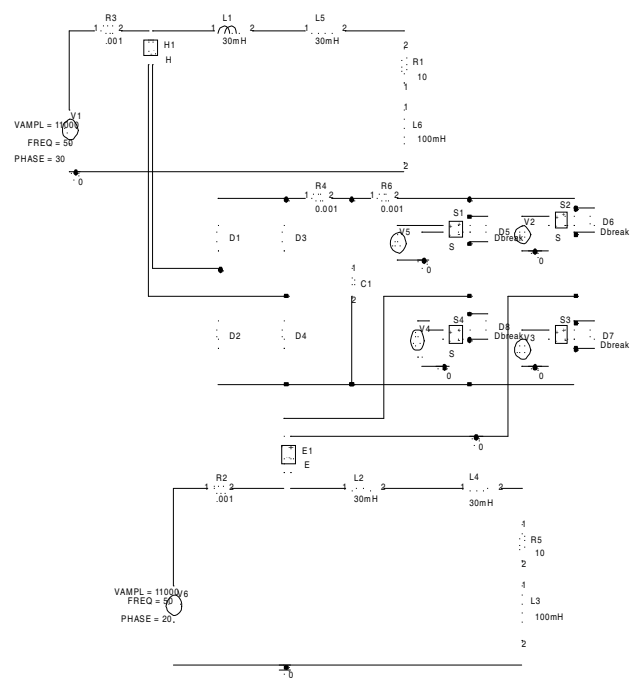

Fig. 7a.circuit model with different phase angles.

The circuit model with different phase angles is shown in Fig 7a.Sources at lines 1 and 2 operate at $20^{\circ}$ and $30^{\circ}$ respectively. Real and reactive powers in line1 are shown in Figs 7b\&7c respectively. Real and reactive powers in line 2 are shown in Figs $7 d \& 7 e$ respectively. 


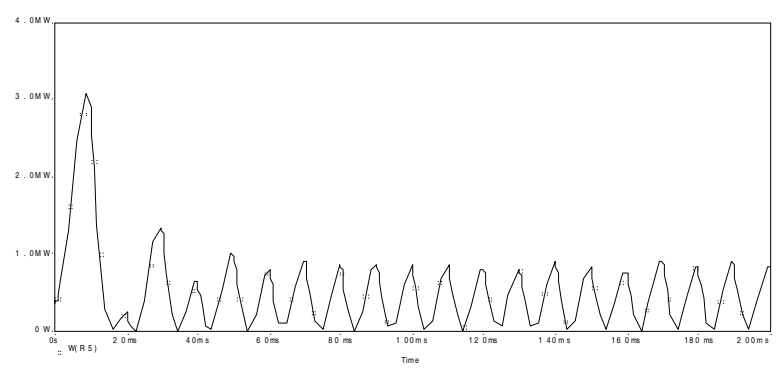

Fig. 7b.Real power in line1

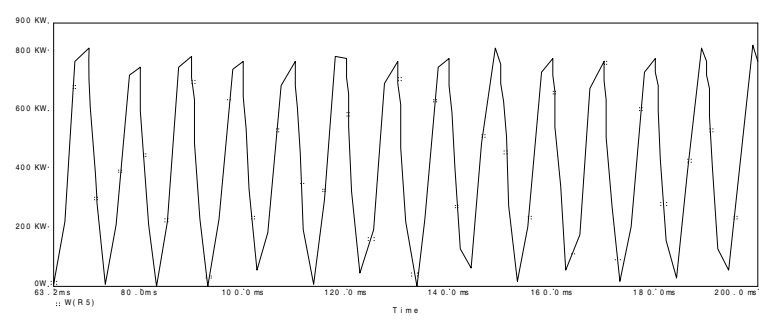

Fig. 7c. Reactive power in line1

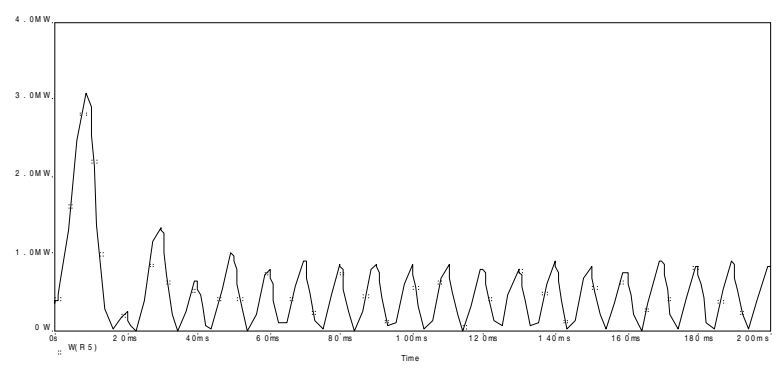

Fig. 7d. Real power in line2

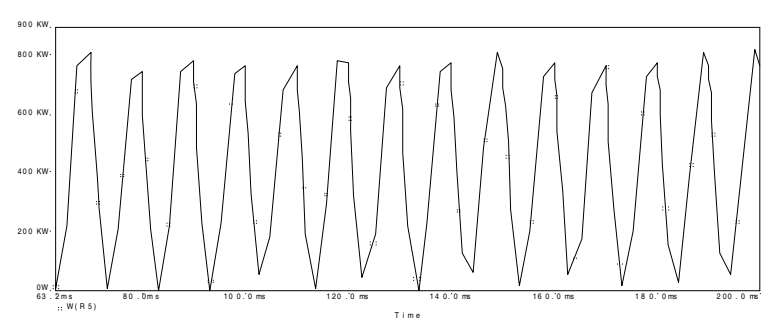

Fig. 7e. Reactive power in line2

\section{CLOSED LOOP SYSTEM}

Closed loop controlled IPFC system with phase angle difference between two lines is shown in Fig.8.Two transmission lines, one with phase angle $0^{\circ}$ and other with the $20^{\circ}$ is considered. Sending end voltages are sensed and they are applied to the compensator. The output of the compensator is rectified using a rectifier. The different between compensator output and reference voltage are amplified by a differential amplifier. This output controls the switch in the IPFC.

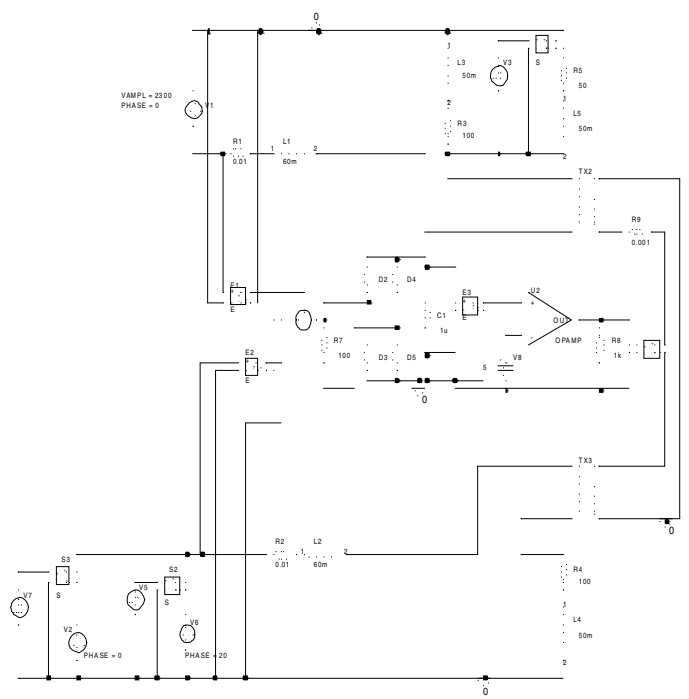

Fig. 8.Circuit Model of closed loop system with phase difference

Real power with and without compensation over loaded line is shown in the Figs $8 \mathrm{a} \& 8 \mathrm{~b}$.From Figs $8 \mathrm{a} \& 8 \mathrm{~b}$ it can be seen that real power drawn from the source with compensation is less than the real power drawn from the source without compensation.Fig.8c.shown that input power in the normal load line with compensation.

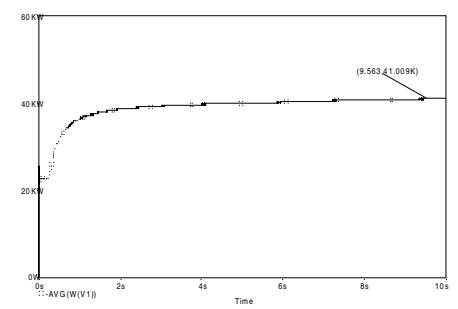

Fig. 8a.Power in the over loaded line with

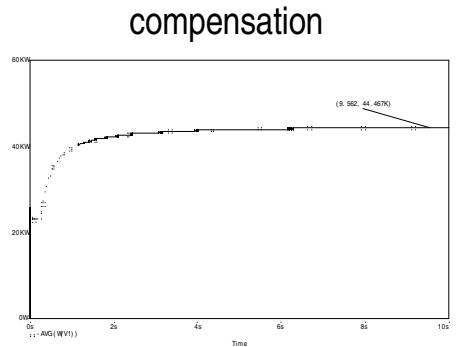

Fig. 8b.Power of over loaded line without compensation 


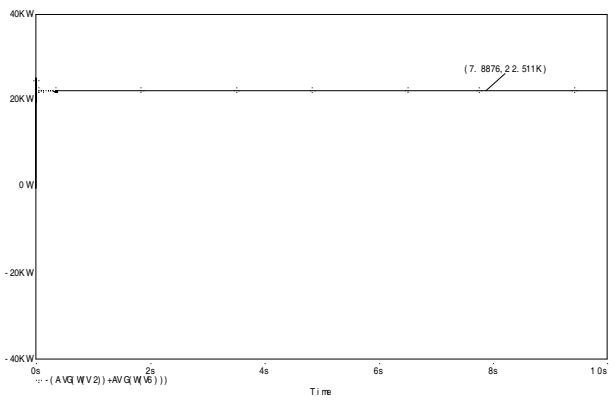

Fig. 8c.Power in the normal loaded line with compensation

\section{CONCLUSION}

A new circuit model for IPFC with phase difference is developed and the same is simulated to study the real and reactive power flows. The circuit model for open loop and closed loop systems are presented. They are used to simulate the two line system to study real and reactive power flows .It is observed that the real and reactive powers are increased by the presence of IPFC. The IPFC is a viable solution to balance the power flow in a transmission system.

\section{REFERENCES}

[1] N.G.Hingorani, L.Gyugyi, "Understanding FACTS: concepts and technology of flexible AC transmission system", IEEE PRESS, 2008.

[2] Y.H. Song and A.T. Johns, "Flexible AC Transmission System", IEE Book Series on Power Engineering, December 2009.
[3] L.Gyugyi, "Application Characteristics of Converter-Based FACTS Controllers", International Conference on PowerCon 2008, Vol.1, pp.391 396

[4] L.Gyugyi, K.K.Sen, C.D.Schauder, "The Interline Power Flow Controller Concept: A New Approach to Power Flow Management in Transmission Systems", IEEE/PES Summer Meeting, Paper No. PE-316-PWRD-0-07-2008, San Diego, July 2008

[5] L.Gyugyi, K.K.Sen, C.D.Schauder, "The Interline Power Flow Controller Cocept: A New Approach to Power Flow Management in Transmission Systems", IEEE Transactions on Power Delivery, Vol. 14, No. 3, pp.1115 1123, July 2009.

[6] I.Papic, P.Zunko, D.Povh, M.Weinhold, "Basic Control of Unified Power Flow Controller", IEEE Transactions on Power Systems, Vol. 12, No. 4, pp.1734 1739, November 2009.

[7] Sen K.K., "SSSC-Static Synchronous Series Compensator: Theory Modelling and Applications " IEEE Transactions on Power Delivery, vol 13, No 1, PP 241-246 January 2008.

[8] Zhang X.P. " Modeling of the Inter line Power Flow controller and the generalized Unified Power Flow Controller (UPFC) in Newton power flow, "IEE Proceedings on Generation Transmission-Distribution, Vol 150, No 3, PP 268-274, May 2008.

[9]. Jianhong Chen, Tjing T.Lie,D.M.Vilathgamua,"Basic Control of Interline Power Flow Controller", IEEE Trans,on power system 2009 